\title{
General Anesthesia-Related Neurotoxicity: Status of Pediatric Surgeries at an Academic Hospital in the North of Iran
}

\author{
Gelareh Biazar (iD ${ }^{1}$, Farnoush Farzi ${ }^{1,{ }^{*}}$, Bahram Naderi Nabi ${ }^{1}$, Zahra Atrkarroushan ${ }^{2}$, Yasmin \\ Chaibakhsh ${ }^{1}$ and Sepideh Rostami Lima ${ }^{2}$ \\ ${ }^{1}$ Anesthesiology Research Center, Department of Anesthesiology, Alzahra Hospital, Guilan University of Medical Sciences, Rasht, Iran \\ ${ }^{2}$ Department of Statistic, Guilan University of Medical Sciences, Rasht, Iran \\ "Corresponding author: Anesthesiology Research Center, Department of Anesthesiology, Alzahra Hospital, Guilan University of Medical Sciences, Rasht, Iran. Email: \\ farnoushfarzi1374@gmail.com
}

Received 2019 April 15; Revised 2019 August 23; Accepted 2019 September 06.

\begin{abstract}
Background: Recently, general anesthesia (GA)-related neurotoxicity has turned into a big concern. However, it seems that inadequate attention has been paid to the issue in Iran.

Objectives: The aim of this survey was to investigate the frequency of elective surgeries in children under the age of three at an academic hospital in the north of Iran.

Methods: This retrospective study was conducted at Alzahra Hospital affiliated to the Guilan University of Medical Sciences (GUMS). The records of all children who had undergone surgeries during 2014 - 2017 were examined by a responsible physician. Then, the records of children under three receiving GA were sorted out. After that, questionnaires with items on gender, habitat, age of receiving GA, type and status (elective or urgency) of surgeries were filled out.

Results: According to our results, 670 children underwent surgery under GA during the study period, while $50.4 \%$ were elective. The mean age of patients was 15.26 months; $9.9 \%$ of them were neonates, $42.4 \%$ were infants, $80.3 \%$ were boys, and $60.7 \%$ were from urban areas. The most affected children were urban boys and the most obviously avoidable surgery was circumcision.

Conclusions: More attention should be paid to the issue of GA-related neurotoxicity at our hospital. Future studies are welcome to examine the issue and find practical interventions.
\end{abstract}

Keywords: General Anesthesia, Neurotoxicity, Pediatrics, Surgery

\section{Background}

According to US reports, annually $10 \%$ of children under five are exposed to general anesthesia (GA) (1). Over the last two decades, a concern has arisen that anesthesia drugs in early life might induce neurotoxicity $(2,3)$. The scientific literature indicates that two major available anesthetic drugs that act as N-methyl-D-aspartic acid receptor antagonists and gamma-aminobutyric acid (GABA) agonists can interfere with brain development. The findings of animal studies brought the concern that similar apoptotic phenomena may affect human brain development when exposed to anesthetic agents (4-10).

This concern led to planning several clinical studies focusing on the potential risks of inducing anestheticrelated neurotoxicity, which reported controversial results $(11,12)$. Some strongly supported this association even after a single exposure (13) while some others reported impaired neurodevelopment following multi-exposures (2,
$14,15)$ and some, in contrast, did not find any significant correlation between early-life GA exposure and impaired neurocognitive function (1). In a birth cohort study, Tsai et al. found that early exposure to GA increased the risk of developing ADHD (16). In contrast, Ko et al. in a retrospective matched cohort study found a non-significant association between GA exposure before the age of three and later behavioral disorders (17). Due to the multiple influencing factors in human studies including socioeconomic status, family, gene-environment interaction, different assessment tools (e.g. intelligence, academic success, behavioral disorders), and comorbidities, the definite findings of experimental studies could not be directly translated to the human brain $(1,14,18,19)$.

Overall, substantial evidence supporting the induced risk of injury by anesthesia in developing neurons, it is wise to obey the rule of postponing unnecessary surgeries and procedures requiring anesthesia or deep sedation in 
young children $(20,21)$. Obviously, depriving the child of anesthesia and analgesia due to the fear of neurotoxicity is not legally and ethically accepted (22). According to our knowledge and literature review, no similar study was found in Iran, let alone in Guilan province. It seems that unlike some other countries that have focused on GArelated neurotoxicity as a significant public health concern, the issue has not been appropriately addressed in our country.

\section{Objectives}

In this study, we investigated the frequency of elective surgeries in children under the age of three and some related factors at an academic hospital in the north of Iran.

\section{Methods}

After the protocol was approved by the Research Ethics Committee of the University (Ref., IR.GUMS.REC.1397.217), a retrospective study was conducted at Alzahra Hospital, an academic, referral center for most types of pediatric surgeries affiliated to the Guilan University of Medical Sciences (GUMS). The records of all children who had undergone surgeries during 2014 - 2017 were studied by a responsible physician. Then, the records of children under three receiving GA were sorted out and files with incomplete required data were excluded. Next, questionnaires were filled out with items on gender, habitat, age of receiving GA, cause and type of sugeries (elective or emergency) of surgeries.

\subsection{Statistical Analysis}

The data were analyzed by SPSS version 16 . The chisquare test and descriptive statistics were applied. A P value of $\leq 0.05$ was considered significant.

\section{Results}

According to results, 670 children under three underwent surgeries during the study period. We found that $50.4 \%$ of the surgeries were elective and $49.6 \%$ of our cases were scheduled for emergency operations. The mean age of children was 15.26 months, including 9.9\% neonates, $42.4 \%$ infants, $80.3 \%$ boys, and $60.7 \%$ from urban areas (Table 1). The relationships between age, gender, habitat, and surgery pattern (emergency-elective) are shown in Table 2. Elective surgeries were significantly more common in boys than in girls $(\mathrm{P}=0.006)$ and in urban children than in rural children $(P=0.045)$. surgery cause are presented in Table 3. On the whole, intussusception (18.50\%) was the most common cause of emergency operations in both genders

\begin{tabular}{cc}
\hline \multicolumn{1}{l}{ Table 1. Characteristics of Children Under Three Exposed to General Anesthesia } \\
\hline Variable/Status & Frequency (\%) \\
\hline Gender & $541(80.7)$ \\
\hline Male & $129(19.3)$ \\
\hline Female & \\
\hline Age, mon & $66(9.9)$ \\
\hline$<1$ & $159(23.7)$ \\
\hline $1-6$ & $125(18.7)$ \\
\hline $6-12$ & $185(27.6)$ \\
\hline $12-24$ & $135(20.1)$ \\
\hline $24-36$ & $15.26 \pm 12.26(36-0.1)$ \\
\hline Age, mo, mean \pm SD & \\
\hline Habitant & $407(60.7)$ \\
\hline Urban & $263(39.3)$ \\
\hline Rural & \\
\hline Surgery types & $332(49.6)$ \\
\hline Emergency & $338(50.4)$ \\
\hline Elective & \\
\hline
\end{tabular}

and hernia (umbilical or inguinal) was the most common cause of elective surgeries (28.95\%), followed by circumcision (16\%) among boys.

\section{Discussion}

The main finding of this study was that $50.4 \%$ of the pediatric surgeries were elective. However, it cannot be well-recognized that how many of these cases could actually be postponed to the age of above three. We can just judge that surgeries such as post-circumcision bleeding, appendicitis, and intussusception are categorized as emergency surgeries while circumcision, for example, is specifically elective surgery. However, regarding other conditions such as axillary or facial masses and herniation, it is unsafe to exactly declare that these surgeries could be postponed. Indeed, since it was a retrospective study, two phrases "elective" or "emergency", like other children's data, were extracted from the documents and the suffering condition of the child was not clear at that time. The potential complications due to the anatomic site of the mass and the communication problems of the child should be considered, as well. Additionally, in a few surgeries, determining the proper age for surgery is multifactorial. For example, in hypospadias surgery, it is suggested that, although it is elective surgery, the complication rate increases as the child age increases. Studies show that fistula is more common in surgery at the age of 10 than younger ages (23). 


\begin{tabular}{|c|c|c|c|c|}
\hline & Emergent & Elective & Total & P Value \\
\hline Age, mo & & & & 0.0001 \\
\hline$<1$ & $64(97)$ & $2(3)$ & 66 & \\
\hline $1-6$ & $35(22)$ & $124(78)$ & 159 & \\
\hline $12-24$ & $98(53)$ & $87(47)$ & 185 & \\
\hline $24-36$ & $57(42.2)$ & $78(57.8)$ & 135 & \\
\hline Gender & & & & 0.006 \\
\hline Male & $254(47)$ & $287(53)$ & 541 & \\
\hline Female & $78(60.5)$ & $51(39.5)$ & 129 & \\
\hline Habitant & & & & 0.045 \\
\hline Urban & $189(46.4)$ & $218(53.6)$ & 407 & \\
\hline Rural & $143(54.4)$ & $120(45.6)$ & 263 & \\
\hline Total & $332(49.6)$ & $338(50.4)$ & 670 & \\
\hline
\end{tabular}

${ }^{\mathrm{a}}$ Values are expressed as No. (\%).

Overall, based on the present study, we cannot claim that, in our hospital, more than half of the children under three undergo unnecessary surgeries and consequently are affected by GA. However, it is quite clear that GA-related neurotoxicity must be more broadly discussed and the conditions regarding pediatric surgery and case selection must be improved. In fact, it should be accepted that GA in young children must be restricted to emergency surgeries and life-treating conditions. We reported these data from our hospital, which is a referral and academic hospital. However, due to the lack of similar studies, we cannot compare our performance with other centers to find out whether we are acting properly or not.

In line with our findings that indicated the need for good communication between anesthesiology departments and other departments, Sedighinejad et al. in a study evaluated the current knowledge and practice of physicians, both specialists and residents, at Guilan academic hospitals regarding GA-related neurotoxicity. They reported that more than half of their participants neither had any idea about GA neurotoxicity nor prevented parents from elective surgeries for their children (24). Searching the literature, our country, Iran, is not the only place experiencing this problem. Ward et al. in 2015 reported that the current pediatric anesthesia programs in the US could not manage the topic of GA neurotoxicity with nonanesthesia colleagues and parents through good communication. Studies have shown that parents frequently ask about the safe age for GA (25).
We believe that despite these limitations, this study can be valued because it would enlighten the public to see the importance of this issue and how it hasn't been wellpracticed. Obviously, many more attempts should be made to reach the desired goals.

\subsection{Limitations}

It was a single-center study, restricted to an academic hospital with two pediatric surgeons. Thus, we have no information about the private hospitals in our province with several surgeons and possibly with different approaches. Furthermore, limitations due to the nature of a retrospective survey should be considered, as well. The investigated factors related to GA exposure in children under three were restricted to those documented in hospital records. Thus, important factors such as parents' education levels could not be evaluated.

\subsection{Conclusions}

This study indicates that more attention should be paid to the issue of GA-related neurotoxicity in our hospital. Furthermore, the vital role of anesthesiologists was highlighted in making better communication with other relevant fields and providing adequate information to parents in their preoperative visits. Well planned prospective studies involving private centers are welcome to achieve more definite findings. 


\begin{tabular}{|c|c|c|}
\hline & Male & Female \\
\hline Herniation & $147(75.8)$ & $47(24.2)$ \\
\hline Circumcision & $107(100)$ & $0(0)$ \\
\hline Intussusception & $86(69.4)$ & $38(30.6)$ \\
\hline Incarcerated herniation & $13(100)$ & $0(0)$ \\
\hline Hypospadias & $21(100)$ & $0(0)$ \\
\hline Herniation + hydrocele & $23(100)$ & $0(0)$ \\
\hline Appendicitis & $5(62.5)$ & $3(37.5)$ \\
\hline Anal fistula & $8(88.9)$ & $1(11.1)$ \\
\hline Ankyloglossia & $8(88.9)$ & $1(11.1)$ \\
\hline Polydactyly & $7(89)$ & $0(0)$ \\
\hline Undescended testicle & $48(100)$ & $0(0)$ \\
\hline Axillary mass & $6(85.7)$ & $1(14.3)$ \\
\hline Pyloric stenosis & $14(88)$ & $2(13)$ \\
\hline Urethral stricture & $4(100)$ & $0(0)$ \\
\hline Facial mass & $4(50)$ & $4(50)$ \\
\hline Perianal abscess & $8(72.7)$ & $3(27.3)$ \\
\hline Labial adhesion & $0(0)$ & $3(100)$ \\
\hline Post circumcision bleeding & $4(100)$ & $0(0)$ \\
\hline Meckel diverticulum & $1(100)$ & $0(0)$ \\
\hline Emphalocele and gastroschisis & $3(50)$ & $3(50)$ \\
\hline Diaphragmatic hernia & $1(20)$ & $4(80)$ \\
\hline Unperforated anus & $15(88)$ & $2(12)$ \\
\hline Intestinal or esophageal atresia & $8(32)$ & $17(68)$ \\
\hline
\end{tabular}

\section{Footnotes}

Authors' Contribution: All the authors were involved in preparing the manuscript. They also read and approved the content of this study.

Conflict of Interests: None of the authors had any conflict of interests regarding this paper.

Ethical Approval: The study protocol was approved by the Research Ethics Committee of the University (Ref., IR.GUMS.REC.1397.217).

Funding/Support: This study was not sponsored.

\section{References}

1. Sun LS, Li G, Miller TL, Salorio C, Byrne MW, Bellinger DC, et al. Association between a single general anesthesia exposure before age 36 months and neurocognitive outcomes in later childhood. JAMA. 2016;315(21):2312-20. doi: 10.1001/jama.2016.6967. [PubMed: 27272582]. [PubMed Central: PMC5316422].
2. Bong CL, Allen JC, Kim JT. The effects of exposure to general anesthesia in infancy on academic performance at age 12. Anesth Analg. 2013;117(6):1419-28. doi: 10.1213/ANE.0b013e318299a7c2. [PubMed: 24132012].

3. Backeljauw B, Holland SK, Altaye M, Loepke AW. Cognition and brain structure following early childhood surgery with anesthesia. Pediatrics. 2015;136(1):e1-12. doi: 10.1542/peds.2014-3526. [PubMed: 26055844]. [PubMed Central: PMC4485006].

4. Rappaport BA, Suresh S, Hertz S, Evers AS, Orser BA. Anesthetic neurotoxicity-clinical implications of animal models. $N$ Engl J Med. 2015;372(9):796-7. doi: 10.1056/NEJMp1414786. [PubMed: 25714157].

5. Loepke AW, Vutskits L. What lessons for clinical practice can be learned from systematic reviews of animal studies? The case of anesthetic neurotoxicity. Paediatr Anaesth. 2016;26(1):4-5. doi: 10.1111/pan.12826. [PubMed: 26644299].

6. Makaryus R, Lee H, Robinson J, Enikolopov G, Benveniste H. Noninvasive tracking of anesthesia neurotoxicity in the developing rodent brain. Anesthesiology. 2018;129(1):118-30. doi: 10.1097/ALN.0000000000002229. [PubMed: 29688900]. [PubMed Central: PMC6008207].

7. Takaenoki Y, Satoh Y, Araki Y, Kodama M, Yonamine R, Yufune S, et al. Neonatal exposure to sevoflurane in mice causes deficits in maternal behavior later in adulthood. Anesthesiology. 2014;120(2):403-15. doi: 10.1097|ALN.0000435846.28299.e7. [PubMed: 24061597].

8. Zou X, Liu F, Zhang X, Patterson TA, Callicott R, Liu S, et al. Inhalation anesthetic-induced neuronal damage in the developing rhesus monkey. Neurotoxicol Teratol.2011;33(5):592-7. doi:10.1016/j.ntt.2011.06.003. [PubMed: 21708249].

9. Paule MG, Li M, Allen RR, Liu F, Zou X, Hotchkiss C, et al. Ketamine anesthesia during the first week of life can cause long-lasting cognitive deficits in rhesus monkeys. Neurotoxicol Teratol. 2011;33(2):22030. doi: 10.1016/j.ntt.2011.01.001. [PubMed: 21241795]. [PubMed Central: PMC3071878].

10. Barton K, Nickerson JP, Higgins T, Williams RK. Pediatric anesthesia and neurotoxicity: What the radiologist needs to know. Pediatr Radiol. 2018;48(1):31-6. doi: 10.1007/s00247-017-3871-4. [PubMed: 28470388].

11. Servick K. Biomedical research. Researchers struggle to gauge risks of childhood anesthesia. Science. 2014;346(6214):1161-2. doi: 10.1126/science.346.6214.1161. [PubMed: 25477435].

12. Hu D, Flick RP, Zaccariello MJ, Colligan RC, Katusic SK, Schroeder DR, et al. Association between exposure of young children to procedures requiring general anesthesia and learning and behavioral outcomes in a population-based birth cohort. Anesthesiology. 2017;127(2):22740. doi: 10.1097/ALN.0000000000001735. [PubMed: 28609302]. [PubMed Central: PMC5515677].

13. Davidson AJ, Becke K, de Graaff J, Giribaldi G, Habre W, Hansen T, et al. Anesthesia and the developing brain: A way forward for clinical research. PaediatrAnaesth. 2015;25(5):447-52. doi:10.1111/pan.12652. [PubMed: 25818094].

14. Wang $\mathrm{X}, \mathrm{Xu} \mathrm{Z}$, Miao $\mathrm{CH}$. Current clinical evidence on the effect of general anesthesia on neurodevelopment in children: An updated systematic review with meta-regression. PLoS One. 2014;9(1). e85760. doi: 10.1371/journal.pone.0085760. [PubMed: 24465688]. [PubMed Central: PMC3896404].

15. Flick RP, Katusic SK, Colligan RC, Wilder RT, Voigt RG, Olson MD, et al. Cognitive and behavioral outcomes after early exposure to anesthesia and surgery. Pediatrics. 2011;128(5):e1053-61. doi: 10.1542/peds.20110351. [PubMed: 21969289]. [PubMed Central: PMC3307194].

16. Tsai CJ, Lee CT, Liang SH, Tsai PJ, Chen VC, Gossop M. Risk of ADHD after multiple exposures to general anesthesia: A nationwide retrospective cohort study. J Atten Disord. 2018;22(3):229-39. doi: 10.1177/1087054715587094. [PubMed: 26023173].

17. Ko WR, Liaw YP, Huang JY, Zhao DH, Chang HC, Ko PC, et al. Exposure to general anesthesia in early life and the risk of attention 
deficit/hyperactivity disorder development: A nationwide, retrospective matched-cohort study. Paediatr Anaesth. 2014;24(7):741-8. doi: 10.1111/pan.12371. [PubMed: 24612161].

18. Ing $C$, DiMaggio $C$, Whitehouse $A$, Hegarty $M K$, Brady J, von UngernSternberg BS, et al. Long-term differences in language and cognitive function after childhood exposure to anesthesia. Pediatrics. 2012;130(3):e476-85. doi: 10.1542/peds.2011-3822. [PubMed: 22908104]

19. Castellheim A, Lundstrom S, Molin M, Kuja-Halkola R, Gillberg C, Gillberg $\mathrm{C}$. The role of general anesthesia on traits of neurodevelopmental disorders in a Swedish cohort of twins. J Child Psychol Psychiatry. 2018;59(9):966-72. doi: 10.1111/jcpp.12885. [PubMed: 29465765].

20. US Food and Drug Administration. FDA Drug Safety Communication: FDA review results in new warnings about using general anesthetics and sedation drugs in young children and pregnant women. Food and Drug Administration; 2017.

21. Yu CK, Yuen VM, Wong GT, Irwin MG. The effects of anaesthesia on the developing brain: a summary of the clinical evidence. F1000Res. 2013;2:166. doi: 10.12688/f1000research.2-166.v2. [PubMed: 24327918] [PubMed Central: PMC3829131].
22. O'Leary JD, Janus M, Duku E, Wijeysundera DN, To T, Li P, et al. A population-based study evaluating the association between surgery in early life and child development at primary school entry. Anesthesiology. 2016;125(2):272-9. doi: 10.1097|ALN.0000000000001200. [PubMed: 27433745].

23. Yildiz T, Tahtali IN, Ates DC, Keles I, Ilce Z. Age of patient is a risk factor for urethrocutaneous fistula in hypospadias surgery. J Pediatr Urol. 2013;9(6 Pt A):900-3. doi: 10.1016/j.jpurol.2012.12.007. [PubMed: 23290687].

24. Sedighinejad A, Soltanipour S, Rimaz S, Biazar G, Chaibakhsh Y, Badri Kouhi M. General anesthesia-related neurotoxicity in the developing brain and current knowledge and practice of physicians at Guilan Academic hospitals. Anesth Pain Med. 2019;9(4). e92366. doi: 10.5812/aapm.92366.

25. Ward CG, Hines SJ, Maxwell LG, McGowan FX, Sun LS. Neurotoxicity, general anesthesia in young children, and a survey of current pediatric anesthesia practice at US teaching institutions. Paediatr Anaesth. 2016;26(1):60-5. doi: 10.1111/pan.12814. [PubMed: 26559907]. 